\title{
One-Step Microwave-Assisted Synthesis and Visible-Light Photocatalytic Activity Enhancement of BiOBr/RGO Nanocomposites for Degradation of Methylene Blue
}

\author{
Kun-Yauh Shih *, Yen-Ling Kuan and En-Rui Wang \\ Department of Applied Chemistry, National Pingtung University, Pingtung 90003, Taiwan; \\ axw13671035@gmail.com (Y.-L.K.); transformersprime12345678@gmail.com (E.-R.W.) \\ * Correspondence: sky@mail.nptu.edu.tw
}

check for updates

Citation: Shih, K.-Y.; Kuan, Y.-L.; Wang, E.-R. One-Step

Microwave-Assisted Synthesis and Visible-Light Photocatalytic Activity Enhancement of $\mathrm{BiOBr} / \mathrm{RGO}$

Nanocomposites for Degradation of Methylene Blue. Materials 2021, 14, 4577. https://doi.org/10.3390/ ma14164577

Academic Editors: Andrea Petrella and Alina Pruna

Received: 8 July 2021

Accepted: 11 August 2021

Published: 15 August 2021

Publisher's Note: MDPI stays neutral with regard to jurisdictional claims in published maps and institutional affiliations.

Copyright: (c) 2021 by the authors. Licensee MDPI, Basel, Switzerland. This article is an open access article distributed under the terms and conditions of the Creative Commons Attribution (CC BY) license (https:// creativecommons.org/licenses/by/ $4.0 /$ )

\begin{abstract}
In this study, bismuth oxybromide/reduced graphene oxide (BiOBr/RGO), i.e. BiOBr-G nanocomposites, were synthesized using a one-step microwave-assisted method. The structure of the synthesized nanocomposites was characterized using Raman spectroscopy, X-ray diffractometry (XRD), photoluminescence (PL) emission spectroscopy, scanning electron microscopy (SEM), transmission electron microscopy (TEM), Fourier-transform infrared spectroscopy (FTIR), and ultravioletvisible diffuse reflection spectroscopy (DRS). In addition, the ability of the nanocomposite to degrade methylene blue $(\mathrm{MB})$ under visible light irradiation was investigated. The synthesized nanocomposite achieved an MB degradation rate of above $96 \%$ within $75 \mathrm{~min}$ of continuous visible light irradiation. In addition, the synthesized BiOBr-G nanocomposite exhibited significantly enhanced photocatalytic activity for the degradation of MB. Furthermore, the results revealed that the separation of the photogenerated electron-hole pairs in the BiOBr-G nanocomposite enhanced the ability of the nanocomposite to absorb visible light, thus improving the photocatalytic properties of the nanocomposites. Lastly, the MB photo-degradation mechanism of BiOBr-G was investigated, and the results revealed that the $\mathrm{BiOBr}-\mathrm{G}$ nanocomposites exhibited good photocatalytic activity.
\end{abstract}

Keywords: photocatalytic activity; bismuth oxybromide; graphene; microwave-assisted synthesis; nanocomposites

\section{Introduction}

Since 1972, the principle and applications of photocatalysis have been extensively investigated. Recently, with the increase in environmental protection awareness, photocatalysis has attracted significant attention for the treatment of environmental pollution and the conversion of solar energy [1-3]. As an advanced oxidation process, photocatalysis generates electron-hole pairs via light irradiation of photocatalysts. This photocatalytic degradation reaction can be attributed to the excitation of electron radiation in the valence band (VB) to the conduction band (CB) and the formation of holes with positive charges in the VB. During photocatalysis, the adsorbed material further reacts with the electron and hole to produce numerous oxidized substances that can degrade some organic pollutants [4,5].

Titanium dioxide $\left(\mathrm{TiO}_{2}\right)$ is a traditional photocatalyst with high photocatalytic activities and low toxicity $[6,7]$. Currently, $\mathrm{TiO}_{2}$ is the most commonly used photocatalytic material owing to its low toxicity, which significantly limits its negative impact on the environment [8]. However, the large band gap of $\mathrm{TiO}_{2}(3.2 \mathrm{eV})$ limits its ability to effectively convert solar energy. This is because it can only be excited by ultraviolet (UV) light $(\lambda<390 \mathrm{~nm})$, which makes up only approximately $7 \%$ of the solar spectrum [9]. To increase the effective utilization of solar energy, researchers have devoted tremendous efforts to developing a new photocatalyst that can perform photocatalysis in the visible light range and clean the environment in an effective and environmentally friendly manner [10]. Bismuth 
oxyhalides ( $\mathrm{BiOX}, \mathrm{X}=\mathrm{Cl}, \mathrm{Br}$, and $\mathrm{I}$ ) have attracted increased attention for the visible light photocatalytic degradation of organic pollutants [11,12]. Liu et al. [13] combined BiOI with $\mathrm{BiOCl}$ or $\mathrm{BiOBr}$ to prepare $\mathrm{BiOI} / \mathrm{BiOCl}$, which exhibited a methyl orange (MO) removal of $78 \%$ after $150 \mathrm{~min}$ visible light irradiation. In addition, Meng et al. [14] utilized Pd surface-modified $\mathrm{BiOBr}$ nanoparticles to degrade phenol and found that the nanoparticles exhibited a $100 \%$ phenol removal after 300 min visible light irradiation. However, the recombination of the photogenerated electrons and holes of BiOX reduces the photocatalytic activity of the catalyst [15]. The high electron and hole recombination rates of BiOX have restricted its further application. [16,17].

Graphene is a well-known special material globally [18]. The lifetime of the electronhole pairs of a photocatalyst can be enhanced by adding graphene materials to the photocatalyst. This is because the high conductivity of graphene reduces charge recombination [19]. Consequently, graphene-based photocatalysts have attracted tremendous attention owing to their photocatalytic efficiency. For example, Liang et al. [20] synthesized $\mathrm{NiFe}_{2} \mathrm{O}_{4}$-reduced graphene oxide (RGO) nanocomposites and found that these materials exhibited $99.1 \%$ methylene blue (MB) removal under $180 \mathrm{~min}$ UV irradiation. In addition, Liu et al. [21] prepared an $\mathrm{RGO}$-wrapped $\mathrm{TiO}_{2}$ hybrid and found that the catalyst exhibited $100 \%$ MB removal under 150 min UV irradiation. Furthermore, Patil et al. [22] synthesized $\mathrm{BiVO}_{4} / \mathrm{Ag} / \mathrm{rGO}$ hybrid architectures and found that the catalyst exhibited approximately 90\% MB dye removal.

Several methods, such as ultrasonication, hydrothermal method, solvent heat method, and the sol-gel method, are used for the synthesis of photocatalysts. In a previous study, an $\mathrm{H}_{3} \mathrm{PW}_{12} \mathrm{O}_{40} / \mathrm{TiO}_{2}$ composite photocatalyst was prepared using a high-intensity ultrasonication method at a low temperature $\left(80{ }^{\circ} \mathrm{C}\right)$. The $\mathrm{H}_{3} \mathrm{PW}_{12} \mathrm{O}_{40} / \mathrm{TiO}_{2}$ photocatalyst exhibited a $95 \% \mathrm{MB}$ degradation rate under $90 \mathrm{~min}$ solar irradiation [23]. In addition, Vadivel et al. [24] synthesized an $\mathrm{Sm}-\mathrm{BiOBr} / \mathrm{rGO}$ composite photocatalyst using a solvothermal method by utilizing methanol as the solvent. The synthesized photocatalyst exhibited promising potential for the degradation of various hazardous chemicals and organic pollutants. Behera et al. [25] synthesized a series of $\mathrm{ZnFe}_{2} \mathrm{O}_{4} @ \mathrm{RGO}$ nanocomposites using hydrothermal and calcination methods and investigated their applications for the degradation of ciprofloxacin. Farhadian et al. [26] synthesized N, S-doped $\mathrm{TiO}_{2}$ (NST), N, S-doped ZnO (NSZ), and their composites with chitosan (NST/CS, NSZ/CS) using the sol gel-hydrothermal method. They found that NST/CS exhibited the highest tetracycline degradation efficiency of $91 \%$ under 20 min visible light exposure. Chamjangali et al. [27] prepared nanoflower-like Ag- $\mathrm{ZnO}$ photocatalysts using a photoreduction and solution precipitation method and investigated their application for the photocatalytic degradation of $\mathrm{MO}$ and $\mathrm{MB}$. Kumar et al. [28] synthesized $\mathrm{Ag} / \mathrm{TiO}_{2}$ by dispersing $\mathrm{Ag}$ nanoparticles into ethanol under sonication, after which $\mathrm{TiO}_{2}$ was added to the ethanol solution. The synthesized catalyst exhibited the photocatalytic degradation of MB under UV-C light irradiation. Liang et al. [29] synthesized magnetic $\mathrm{Fe}_{3} \mathrm{O}_{4} @ \mathrm{BiOI} @ \mathrm{AgI}$ spheres using a multi-step process. The synthesized spheres exhibited excellent visible light driving activity against $\mathrm{RhB}, \mathrm{BPA}$, and E. coli cells. Sanaa et al. [30] synthesized yBiOBr-(1-y)BHO heterojunction using hydrothermal synthesis and solution mixing methods, and the heterojunction exhibited enhanced visible-light photocatalytic properties. Some researchers have synthesized nanocomposites by combining $\mathrm{BiOBr}$ and graphene and investigated their potential for the degradation of organic pollutants in wastewater. Jiang et al. [31] synthesized BiOBr-RGO nanocomposites using the hydrothermal method, and they found that the nanocomposites exhibited 100\% nitrobenzene degradation after $360 \mathrm{~min}$ visible light irradiation. These studies indicate that the introduction of $\mathrm{RGO}$ to $\mathrm{BiOBr}$ could enhance its visible-light photocatalytic activity. Janani et al. [32] synthesized a magnetic RGO-BiOBr (MRGO-BiOBr) composite by subjecting MRGO and $\mathrm{BiOBr}$ to ultrasonication separately for $30 \mathrm{~min}$, after which they were mixed together under magnetic stirring for $24 \mathrm{~h}$. The effects of parameters, such as catalytic dose and initial dye concentration, were investigated under visible light 
irradiation. The results revealed that the composite exhibited $76.24 \% \mathrm{MB}$ dye removal after 120 min visible light irradiation.

However, the large energy consumption and long reaction time of these methods have limited their further application. To overcome these challenges, in this study, we employed a simple, efficient, time-saving, and environmentally friendly, one-step synthesis method for the synthesis of photocatalyst nanocomposites. The fabrication of nanomaterials using microwaves is an environmentally friendly and cost-effective method. In addition, the microwave-assisted method can obtain high-purity products, improve product yields, and increase reproducibility [33]. In this study, $\mathrm{BiOBr}$, a photocatalyst with visible light photocatalytic ability, was selected and combined with RGO to synthesize a BiOBr/RGO (BiOBr-G) photocatalyst. Furthermore, the microwave-assisted method was employed to synthesize $\mathrm{BiOBr}-\mathrm{G}$ within short durations, and the photocatalytic activity of these nanomaterials was investigated. In addition, the crystal structure, morphology, functional groups, absorption spectra, and photocatalytic mechanism were investigated using various methods. The photocatalytic activity of the nanocomposites was investigated by evaluating their $\mathrm{MB}$ degradation ability. $\mathrm{BiOBr}$ and $\mathrm{BiOBr}-\mathrm{G}$ photocatalysts were successfully synthesized, and their pollutant degradation abilities were investigated. Lastly, their effects on electron-hole pair separation were also discussed.

\section{Materials and Methods}

\subsection{The Materials Used}

Bismuth nitrate $\mathrm{Bi}\left(\mathrm{NO}_{3}\right)_{3} \cdot 5 \mathrm{H}_{2} \mathrm{O}$ was obtained from Sigma-Aldrich (St. Louis, $\mathrm{MO}$, USA). Potassium bromide ( $\mathrm{KBr}$ ) and natural graphite powder $(99.99 \%$, metals basis) were purchased from Alfa Aesar (Haverhill, MA, USA). All of the chemicals used in the study were of analytical grade. The aqueous solutions were prepared using deionized (DI) water.

\subsection{Preparation of Graphene Oxide}

In this study, GO was synthesized from graphite powder using the modified Hummers method [34]. Briefly, $70 \mathrm{~mL}$ of concentrated sulfuric acid (Japan Chemicsl Industries Co. Ltd, Shimizu-ku, Japan ) was placed in an ice bath and cooled to $5{ }^{\circ} \mathrm{C}$. Subsequently, graphite powder, $\mathrm{NaNO}_{3}$, and $\mathrm{KMnO}_{4}$ were added into the flask and stirred evenly for $2 \mathrm{~h}$. Thereafter, $300 \mathrm{~mL}$ of DI water and $10 \mathrm{~mL}$ of $30 \%$ hydrogen peroxide were added to the solution to stop the reaction. Subsequently, the solution was subjected to suction filtration, after which the product was placed in $500 \mathrm{~mL}$ of $5 \%$ hydrochloric acid and stirred $30 \mathrm{~min}$ to remove the remaining metal ions. Thereafter, the $\mathrm{HCl}$ solution was removed and washed with DI water several times until the $\mathrm{pH}$ of the GO suspension was neutral. Lastly, the suspension was filtrated and dried in an oven for $12 \mathrm{~h}$ at $70{ }^{\circ} \mathrm{C}$ to obtain the GO powders.

\subsection{Synthesis of the BiOBr-G Nanocomposites}

$\mathrm{BiOBr}-\mathrm{G}$ nanocomposites with various $\mathrm{GO}$ weight percentages were synthesized using the microwave-assisted method. Briefly, $0.4608 \mathrm{~g} \mathrm{Bi}\left(\mathrm{NO}_{3}\right)_{3} \cdot 5 \mathrm{H}_{2} \mathrm{O}$ was dissolved in $25 \mathrm{~mL}$ of ethylene glycol, after which the mixture was dispersed in an ultrasonic bath for $15 \mathrm{~min}$. Simultaneously, GO powders were dissolved in $10 \mathrm{ml}$ of ethylene glycol, after which the mixture was subjected to magnetic stirring for $30 \mathrm{~min}$. Subsequently, $0.2380 \mathrm{~g}$ of $\mathrm{KBr}$ was added to the $\mathrm{Bi}\left(\mathrm{NO}_{3}\right)_{3} \cdot 5 \mathrm{H}_{2} \mathrm{O}$ solution, after which the mixture was stirred at room temperature for $0.5 \mathrm{~h}$. Thereafter, the GO solution was carefully added to the afore-mentioned solution, and the solution was stirred continuously for $30 \mathrm{~min}$. Subsequently, the mixture was transferred into a $50 \mathrm{~mL}$ Teflon-lined vessel, and the mixture was maintained at $90{ }^{\circ} \mathrm{C}$ for $15 \mathrm{~min}$. The precipitates were collected by centrifugation and washed three times with DI water and ethanol. Thereafter, the precipitates were dried in an oven at $80^{\circ} \mathrm{C}$ overnight. For comparison, pure $\mathrm{BiOBr}$ and $\mathrm{RGO}$ were also prepared using a similar process. The BiOBr-G nanocomposites with RGO content of $0.5,1$, and $5 \mathrm{wt} \%$ were labeled as BiOBr-G0.5, BiOBr-G1, and BiOBr-G5, respectively. The schematic illustration of the synthesis process is shown in Figure 1. 


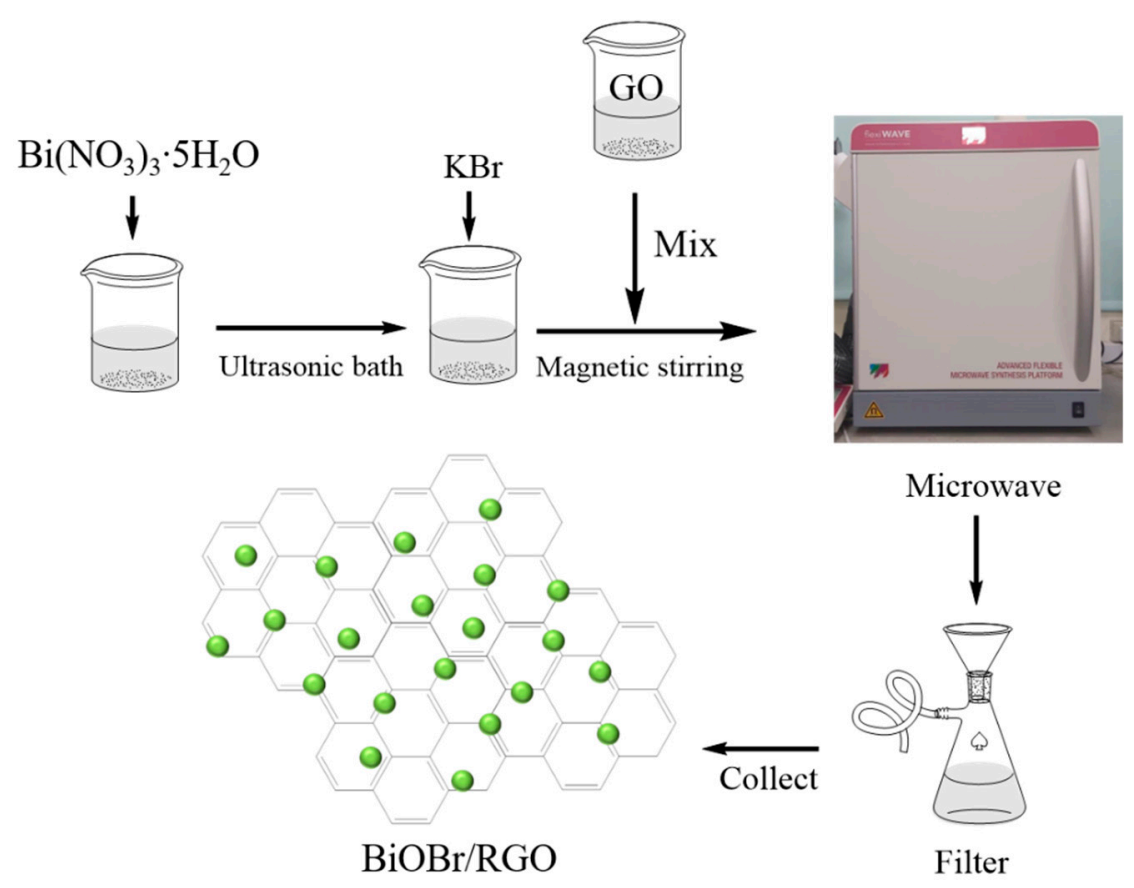

Figure 1. Schematic illustration of the synthesis process of the BiOBr-G nanomaterial.

\subsection{Photocatalytic Activity}

The photocatalytic efficiency of the BiOBr-Gs nanocomposites was investigated. The photocatalytic reactions of the nanocomposites were investigated using a PCX50B Discover multi-channel photoreactor (Perfect Light Technology Ltd, Beijing, China). A $5 \mathrm{~W}$ white light Light-emitting diode lamp was used as the light source to provide visible light with a wavelength of above $420 \mathrm{~nm}$. The MB used in this study was a model pollutant that must be removed. To prepare the sample used for the photocatalytic analysis, $30 \mathrm{mg}$ of as-prepared samples was weighed into a quartz flask, after which $50 \mathrm{~mL}$ of $2 \times 10^{-5} \mathrm{M} \mathrm{MB}$ solution was added. Subsequently, the solution was stirred in the dark for $10 \mathrm{~min}$ to achieve adsorption-desorption equilibrium, after which the solution was subjected to irradiation. The photocatalytic reaction was carried out under visible light irradiation for $75 \mathrm{~min}$, and $3 \mathrm{~mL}$ of the as-prepared solution was collected every $15 \mathrm{~min}$. The collected MB solutions were centrifuged (14,000 RPM, $3 \mathrm{~min})$ to remove the sample powder. The degradation of $\mathrm{MB}$ was evaluated by measuring the characteristic absorption of MB solution at 664 nm using a CT-2200 UV-vis spectrophotometer (ChromTech Co. Ltd; Apple Valley, MN, USA). After measurement, the collected samples were re-injected to the quartz flask, and the experimental condition was maintained.

The removal efficiency of the target pollutant was determined using the following equation:

$$
\operatorname{Removal}(\%)=\left(1-\frac{C_{t}}{C_{0}}\right) \times 100 \%
$$

where $C_{0}$ and $C_{t}$ are the initial concentration and concentration of $M B$ at time $t$, respectively.

\subsection{Characterization}

The as-synthesized BiOBr-G nanocomposites were synthesized using a microwave (Flexiwave T660, Milestone srl, Sorisole, Italy). The crystal structure of the as-synthesized nanocomposites was analyzed using powder X-ray diffraction (XRD, D8A25 eco, BRUKER Co. Ltd, Billerica, MA, USA) with CuK $\alpha$ X-ray radiation $(\lambda=1.5418 \AA)$ operated at $40 \mathrm{kV}$ and $25 \mathrm{~mA}$. The morphology of the particles was observed using transmission electron microscopy (TEM, Hitachi H-7500, Tokyo, Japan) at an accelerating voltage of $80 \mathrm{kV}$. The surface morphology of the samples was investigated using scanning electron microscopy (SEM, Jeolism -6930, Tokyo, Japan) equipped with a system of energy-dispersive spec- 
troscopy (EDS, INCAx act, Munich, Germany). The photoluminescence (PL, Hitachi F-7000, Tokyo, Japan) spectra of the samples were obtained using a Hitachi F-7000 (Tokyo, Japan) spectrometer at an emission wavelength of $300 \mathrm{~nm}$. The Raman spectra were determined using a Princeton Instruments Acton SP2500 (Acton, MA, USA) monochromatic/photographic spectrometer equipped with a nitrogen-cooled CCD detector and a Spec-10 system. The light absorption properties of the samples were investigated using UV-vis diffuse reflectance spectroscopy (DRS, JASCO IBXL0005-V770-EA, JASCO, Tokyo, Japan). The chemical state of the composites was measured using Fourier-transform infrared spectrometer (FT-IR, JASCO FT/IR-6700, JASCO, Tokyo, Japan). A multi-channel photochemical reaction system (Perfect Light Technology Ltd, PCX-50B, Beijing, China) was used during the photocatalytic reaction experiment. The MB concentration was measured using a CT-2200 ultraviolet-visible (UV-Vis) spectrophotometer (ChromTech Co. Ltd.; Apple Valley, MN, USA).

\section{Results}

\subsection{Characterization of BiOBr and $\mathrm{BiOBr}-\mathrm{G}$ \\ 3.1.1. XRD Analysis}

The GO, RGO, BiOBr, and the BiOBr-G nanocomposites synthesized using the microwaveassisted method were analyzed using XRD (Figure 2). The XRD pattern of the GO exhibited a distinct strong reflex at $2 \theta=12.6^{\circ}$, corresponding to the (001) crystal plane of GO. In addition, notable peaks were observed in the XRD pattern of the RGO at $2 \theta=25.0^{\circ}$ and $43.1^{\circ}$, corresponding to the RGO (002) and (102) crystal plane, respectively [35]. However, the (001) crystal plane of GO was not observed in the XRD pattern of the RGO, confirming the successful reduction of GO by the microwave-assisted method. The XRD patterns of $\mathrm{BiOBr}$ and $\mathrm{BiOBr}-\mathrm{G}$ nanocomposites were consistent with the standard card number of pure tetragonal phase BiOBr (JCPDS 09-0393) [36]. The main peaks of the XRD pattern were observed at $2 \theta=10.9^{\circ}, 25.3^{\circ}, 31.7^{\circ}, 32.3^{\circ}, 39.3^{\circ}, 46.3^{\circ}$, and $57.2^{\circ}$, corresponding to the (001), (101), (102), (110), (112), (200), and (212) crystal planes, respectively [37]. However, the (001) crystal plane of GO was not observed in the XRD patterns of all the BiOBr-G samples, confirming the successful reduction of GO. Furthermore, the typical diffraction peaks of RGO at $2 \theta=25.0^{\circ}$ and $43.1^{\circ}$ were not observed in the XRD patterns of the BiOBr-G nanocomposites, which could be attributed to the relatively low diffraction peak intensity of RGO [38].

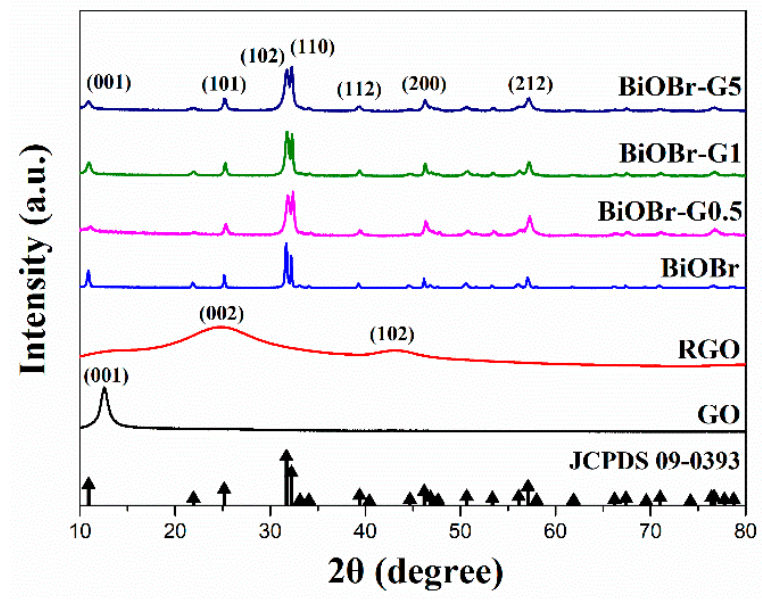

Figure 2. The XRD spectra of GO, RGO, BiOBr, and BiOBr-G samples (Black arrow show a standard card JCPDS 09-0393 of pure BiOBr).

\subsubsection{Raman Spectrum}

Figure 3 shows the Raman spectrum of GO, RGO, and BiOBr-G. Two notable bands, the $\mathrm{D}$ and $\mathrm{G}$ bands, were observed in the Raman spectra of GO and RGO, respectively. The $\mathrm{D}$ band corresponded to the k-point phonon mode, which could be attributed to the $\mathrm{sp}^{3}$ defects in the carbon material, such as vacancies and edge effect. The G band could be 
attributed to the $\mathrm{sp}^{2}$ carbon atoms vibration model $[39,40]$. The D and G bands of GO were observed at $1348 \mathrm{~cm}^{-1}$ and $1587 \mathrm{~cm}^{-1}$, respectively. In addition, the D and G bands of RGO were observed at $1343 \mathrm{~cm}^{-1}$ and $1572 \mathrm{~cm}^{-1}$, respectively. However, no notable peak was observed in the Raman spectrum of BiOBr. In addition, two bands were observed in the Raman spectrum of BiOBr-G at 1365 and $1601 \mathrm{~cm}^{-1}$. The $\mathrm{D}$ band to $\mathrm{G}$ band intensity ratio of BiOBr-G $\left(\mathrm{I}_{\mathrm{D}} / \mathrm{I}_{\mathrm{G}}=0.99\right)$ was slightly lower than that of the pure $\mathrm{GO}\left(\mathrm{I}_{\mathrm{D}} / \mathrm{I}_{\mathrm{G}}=1.01\right)$. This confirms the decrease in the $\mathrm{sp}^{3}$ domain of the carbon atoms in $\mathrm{BiOBr}-\mathrm{G}$ and the increase in the production of the graphene $\mathrm{sp}^{2}$ structure in BiOBr-G. According to the literature, these results correspond to the high electron transport rate of $\mathrm{BiOBr}-\mathrm{G}$ [41,42]. In addition, the $\mathrm{I}_{\mathrm{D}} / \mathrm{I}_{\mathrm{G}}$ value of BiOBr-G was higher than that of $\mathrm{RGO}\left(\mathrm{I}_{\mathrm{D}} / \mathrm{I}_{\mathrm{G}}=0.89\right)$, indicating that the RGO loaded with BiOBr has more defects than RGO. The shift of the D and G band in the BiOBr-G Raman spectrum confirmed that the microwave-assisted synthesis achieved both the reduction of GO and the formation of Bi-OBr-G [24,43].

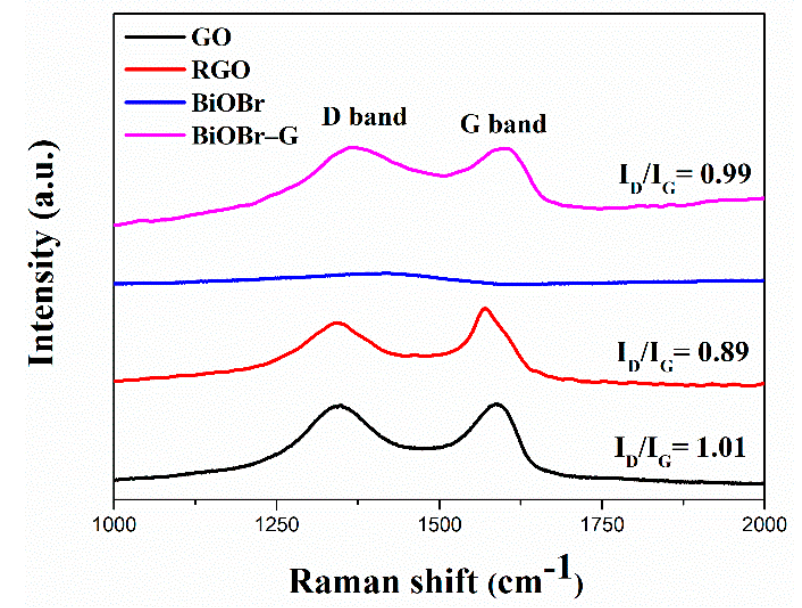

Figure 3. Raman spectra of the GO, RGO, BiOBr, and BiOBr-G nanocomposites. $\mathrm{I}_{\mathrm{D}} / \mathrm{I}_{\mathrm{G}}$ is the ratio of the integrated intensities of the D and G bands.

\subsubsection{FTIR Spectroscopy}

The FT-IR spectra of BiOBr and BiOBr-G nanocomposites are shown in Figure 4. A notable band was observed in the FT-IR spectra of the BiOBr nanosheets at $514 \mathrm{~cm}^{-1}$, which could be attributed to the typical symmetric $\mathrm{A}_{2 \mathrm{u}}$ type of the $\mathrm{Bi}-\mathrm{O}$ bond vibrations. In addition, a similar band was observed in the FT-IR spectra of the BiOBr-G nanocomposite $[44,45]$. Furthermore, a wider absorption band was observed in the FT-IR spectra of these samples at $3404 \mathrm{~cm}^{-1}$, which could be attributed to the $\mathrm{O}-\mathrm{H}$ stretching mode of adsorbed water or hydroxyl groups $[46,47]$. Moreover, the BiOBr-G sample exhibited the typical FT-IR spectrum of BiOBr-G. This indicates that the addition of $\mathrm{GO}$ to $\mathrm{BiOBr}$ during the microwave-assisted synthesis had no effect on the crystal structure of $\mathrm{BiOBr}[48]$.

\subsubsection{Morphological Characterization}

Figure $5 \mathrm{a}, \mathrm{b}$ show the SEM image of $\mathrm{BiOBr}$ and $\mathrm{BiOBr}-\mathrm{G}$ nanocomposites. The pure $\mathrm{BiOBr}$ exhibited a thin flake structure with a two-dimensional relatively smooth surface, which was assembled to flower-like microstructures [49]. However, the BiOBr-G nanocomposite exhibited a spherical structure formed by the assembly of smaller and denser nanosheets. This indicates that the addition of RGO affected the crystallization process of $\mathrm{BiOBr}$ and destroyed the existing micro-flower nanostructure of $\mathrm{BiOBr}$, thus increasing the dispersion and photocatalytic activity of BiOBr-G [50]. Furthermore, TEM was conducted to investigate the structural characteristics of the $\mathrm{BiOBr}$ and $\mathrm{BiOBr}-\mathrm{G}$ nanocomposites, and the results are shown in Figure 5c, d. As shown in Figure 5c, BiOBr exhibits a thin sheet stacked structure with a flat surface, which is consistent with the SEM results and observation [51]. After the addition of RGO, the particle size of BiOBr reduced significantly, and the dispersion on the wrinkled RGO increased. This indicated the successful prepara- 
tion of BiOBr-G. This is because RGO effectively controlled the crystal size of BiOBr and prevented the agglomeration of nanoparticles [52]. In addition, after the addition of RGO, the surface area of the BiOBr-G nanocomposite in contact with dye increased compared to that of pure $\mathrm{BiOBr}$ owing to its smaller particle size. Consequently, the electron transfer and photocatalytic activity of $\mathrm{BiOBr}$ were significantly enhanced [53].

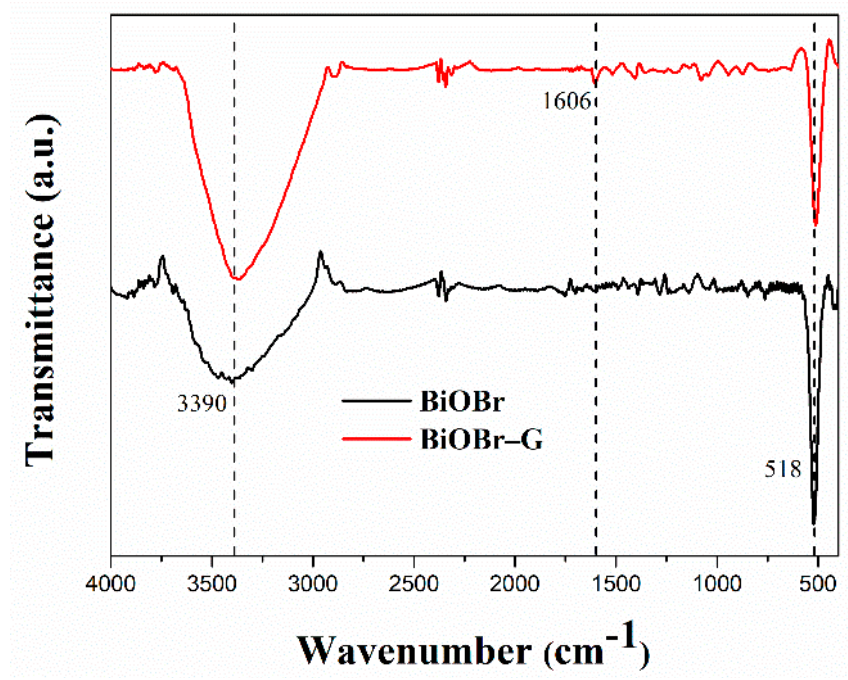

Figure 4. The FTIR spectrum of $\mathrm{BiOBr}$ and $\mathrm{BiOBr}-\mathrm{G}$ nanocomposites.

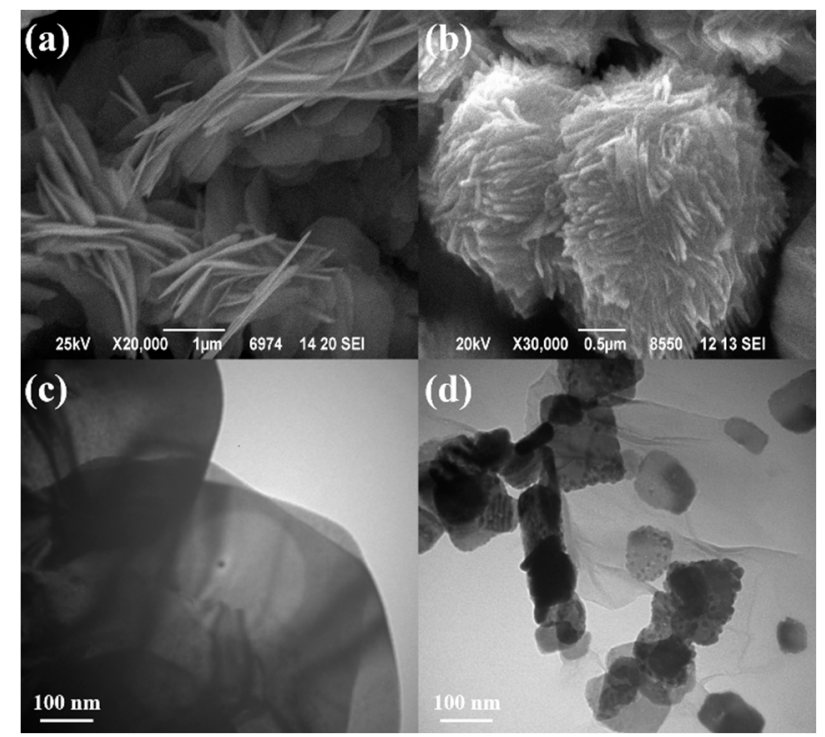

Figure 5. SEM images of (a) $\mathrm{BiOBr}$ and (b) BiOBr-G. TEM images of (c) $\mathrm{BiOBr}$ and (d) $\mathrm{BiOBr}-\mathrm{G}$.

\subsubsection{UV-Vis Diffuse Reflectance Spectra}

Figure 6a shows the UV-Vis diffuse reflectance spectra (DRS) results of BiOBr and $\mathrm{BiOBr}-\mathrm{G}$ nanocomposites. As shown in the image, both $\mathrm{BiOBr}$ and $\mathrm{BiOBr}-\mathrm{G}$ exhibit a wide and high absorption in the visible light range. In addition, the absorption peak of $\mathrm{BiOBr}$ was observed at $445 \mathrm{~nm}$. After adding RGO, the $\mathrm{BiOBr}-\mathrm{G}$ absorption edge slightly red-shifted to $462 \mathrm{~nm}$. The optical band gap $\left(\mathrm{E}_{\mathrm{g}}\right)$ of the $\mathrm{BiOBr}$ and $\mathrm{BiOBr}-\mathrm{G}$ composites was obtained using the Tauc relation, as follows [54]:

$$
\alpha \mathrm{h} v=\mathrm{A}\left(\mathrm{h} v-\mathrm{E}_{\mathrm{g}}\right)^{\mathrm{n} / 2}
$$

where A is a constant, which depends on the transition probability; $h$ is the Planck constant; $v$ is the frequency of light; $\alpha$ is the absorption coefficient; and $\mathrm{n}$ is based on the transition property of the semiconductor [55]. For example, $\mathrm{n}=2$ corresponds to the indirect 
transition of the semiconductor, whereas $n=1 / 2$ corresponds to the direct transition of the semiconductor. Previous studies have reported that the $\mathrm{n}$ of $\mathrm{BiOBr}$ is 2, indicating that the transition property of $\mathrm{BiOBr}$ is indirect [56]. The plot of $(\alpha \mathrm{hv})^{1 / 2} \mathrm{vs}$. the photon energy is shown in Fig. 6b. As shown in the image, the $\mathrm{E}_{\mathrm{g}}$ value of the $\mathrm{BiOBr}$ and $\mathrm{BiOBr}-\mathrm{G}$ nanocomposites are 2.83 and $2.69 \mathrm{eV}$, respectively. The $\mathrm{E}_{\mathrm{g}}$ value of the $\mathrm{BiOBr}$ is similar to the previous study [24].

(a)

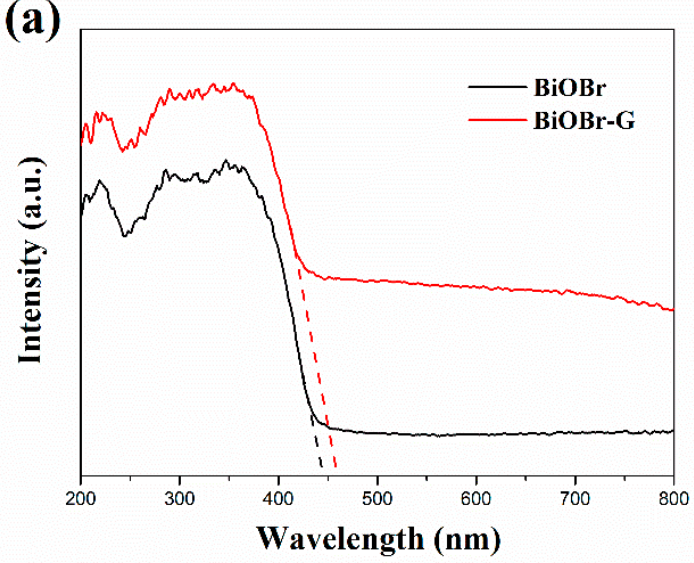

(b)

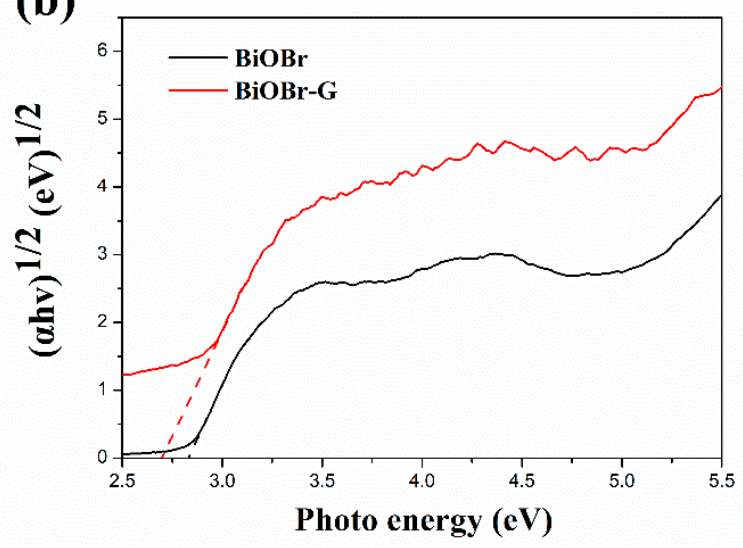

Figure 6. (a) Diffuse reflectance spectra (DRS) and (b) Tauc plots of the BiOBr and BiOBr-G nanocomposites.

\subsubsection{PL Analysis}

The PL spectra of BiOBr and BiOBr-G were obtained to investigate their electron-hole recombination properties. With an increase in the PL intensity of a sample, its photon separation rate decreases, thus increasing the electron-hole pair recombination. Consequently, this reduces the photocatalytic activity of the sample [57]. Figure 7 shows the PL spectrum of the as-synthesized $\mathrm{BiOBr}$ and $\mathrm{BiOBr}-\mathrm{G}$ nanocomposites at an exciting wavelength $\left(\lambda_{\text {ex }}\right)$ of $300 \mathrm{~nm}$. The highest peaks of $\mathrm{BiOBr}$ and $\mathrm{BiOBr}-\mathrm{G}$ were observed at $468 \mathrm{~nm}$. However, the PL spectral intensity of the pure $\mathrm{BiOBr}$ was significantly stronger than that of BiOBr-G. With an increasing in the RGO content, the intensity of the BiOBr-G emission peak decreased, indicating that the addition of RGO enhanced the separation of carriers. These results confirmed that photoelectrons moved from $\mathrm{BiOBr}$ to $\mathrm{RGO}$ and that RGO facilitated the suppression of the electron-hole pair recombination [58]. This indicates that a higher quantum efficiency can be achieved during photocatalytic reactions by utilizing the hierarchical structure of BiOBr-G.

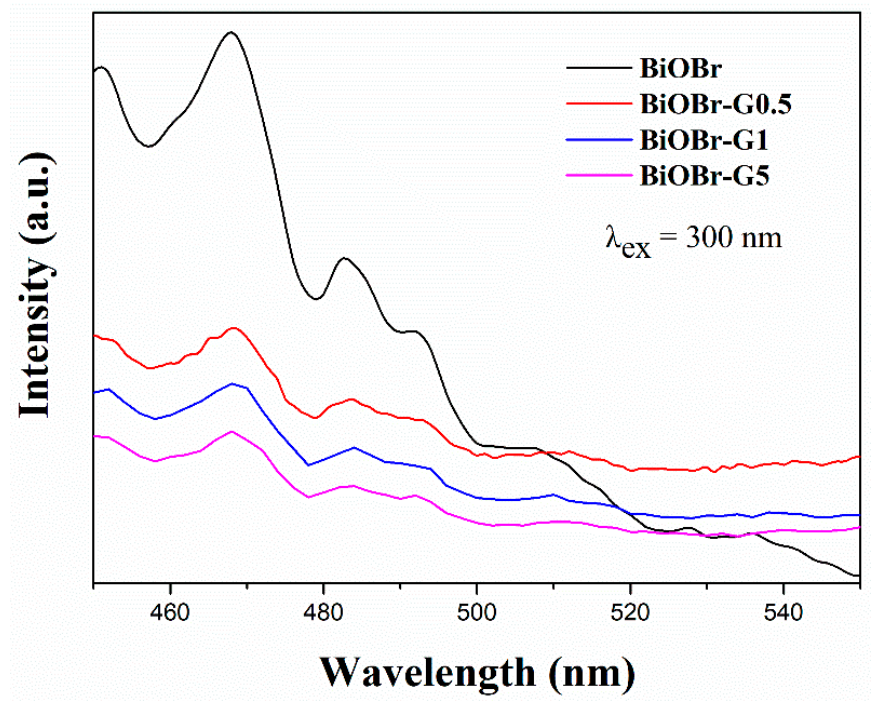

Figure 7. PL spectra of the as-synthesized samples. $\lambda_{\mathrm{ex}}$ is the wavelength of fluorescence excitation. 


\subsection{Photocatalytic Activity}

To investigate the photocatalytic properties of the fabricated samples, the MB degradation properties of commercial $\mathrm{TiO}_{2}(\mathrm{P} 25), \mathrm{BiOBr}$, and each $\mathrm{BiOBr}-\mathrm{G}$ sample under visible light were investigated (Figure 8a). The results revealed that the pure MB did not exhibit self-degrading properties under visible light; however, the addition of the photocatalyst significantly improved the removal efficiency [59]. The order of MB removal percentage of each material was: $\mathrm{TiO}_{2} \mathrm{P} 25(29.74 \%)<\mathrm{BiOBr}(67.25 \%)<\mathrm{BiOBr}-\mathrm{G} 0.5(71.37 \%)<\mathrm{BiOBr}-\mathrm{G} 1$ $(90.80 \%)<$ BiOBr-G5 $(96.41 \%)$. The photocatalytic activity of P25 under visible light was lower than those of the other samples, which could be attributed to the fact that the band gap of P25 is higher than that of $\mathrm{BiOBr}$ and $\mathrm{BiOBr}-\mathrm{Gs}$. This indicates that the P25 sample exhibited the lowest $\mathrm{MB}$ removal rate compared to the other samples. In addition, the photocatalytic activity of all the BiOBr-G nanocomposites was significantly higher than that of $\mathrm{BiOBr}$. These findings are consistent with the PL spectra in Figure 7. Furthermore, the photoelectron-hole pair separation efficiency of the BiOBr-G sample was higher than that of the $\mathrm{BiOBr}$ sample, and it also exhibited an optimum photocatalytic activity performance. The addition of $\mathrm{RGO}$ to $\mathrm{BiOBr}$ significantly enhanced the photocatalytic activity of $\mathrm{BiOBr}$, with the optimum RGO concentration being $5 \mathrm{wt} \%$. In addition, the photo-induced electron transfer rate from the BiOBr surface to the RGO surface increased with an increase in the RGO loading, thus increasing the photocatalytic activity of the BiOBr-G nanocomposite. The prepared photocatalyst follows the first-order kinetic model (Figure $8 b$ ), which can be expressed using the following equation [60]:

$$
-\ln \frac{\mathrm{C}_{0}}{\mathrm{C}_{\mathrm{t}}}=\mathrm{kt}
$$

where $\mathrm{k}$ and $\mathrm{t}$ are the rate constant and lighting time, respectively. The $\mathrm{k}$ values of P25, BiOBr, BiOBr-G0.5, BiOBr-G1, and BiOBr-G5 are 0.00426, 0.0090, 0.0313, 0.0370, and $0.0392 \mathrm{~min}^{-1}$, respectively. The increase in the $\mathrm{k}$ value of BiOBr-G compared to that of $\mathrm{BiOBr}$ indicates the short-term degradation of $\mathrm{MB}$ dye. In addition, the BiOBr-G5 nanocomposite exhibited the optimum photocatalytic effect, which was 4.36 times higher than that of $\mathrm{BiOBr}$. This result indicates that the addition of graphene to $\mathrm{BiOBr}$ significantly improved the photocatalytic efficiency of $\mathrm{BiOBr}$ [61]. Table 1 shows the comparison of the $\mathrm{MB}$ removal and rate constant of $\mathrm{BiOBr}-\mathrm{G} 5$ to those of different materials investigated in previous studies. The MB-removal percentage of BiOBr-G5 was similar to that of other materials; however, the rate constant of BiOBr-G5 was higher than those of the other materials. This result illustrates the enhanced MB-removal efficiency of BiOBr-G5.
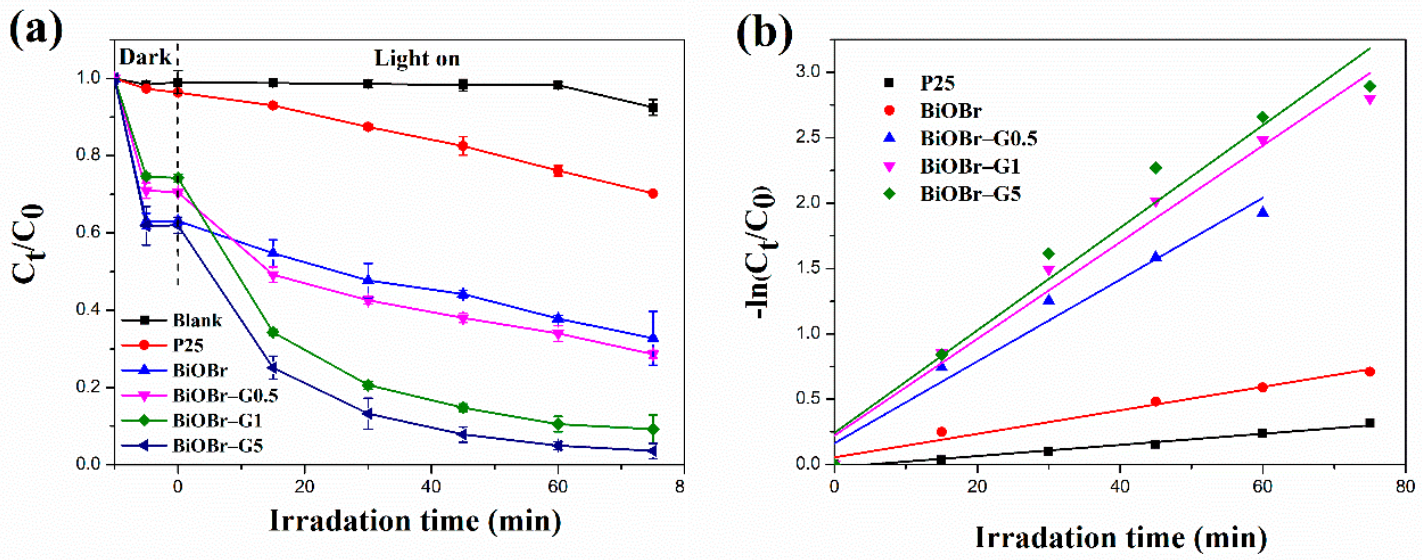

Figure 8. (a) Photocatalytic degradation of MB by P25, BiOBr, and BiOBr-Gs. (b) Photocatalytic kinetic of P25, BiOBr, and $\mathrm{BiOBr}-\mathrm{Gs}$. 
Table 1. MB removal rate and kinetic constant of various catalysts reported in previous studies.

\begin{tabular}{cccc}
\hline Atalyst & MB Removal (\%) & Rate Constant $\left.\mathbf{m i n}^{-1}\right)$ & References \\
\hline $\mathrm{BiOBr}-\mathrm{G} 5$ & 96.41 & 0.0392 & This work \\
$\mathrm{NiFe} \mathrm{O}_{4}-\mathrm{RGO}$ & 99.1 & 0.0199 & {$[20]$} \\
$\mathrm{Ag}-\mathrm{ZnO}$ & $\sim 100$ & - & {$[27]$} \\
$\mathrm{Ag} / \mathrm{TiO}_{2}$ & $36 \sim 90$ & $0.001 \sim 0.008$ & {$[28]$} \\
$\mathrm{BG}-6$ & 100 & 0.0087 & {$[31]$} \\
$\mathrm{NiFe}_{0.5} \mathrm{Nd}_{1.5} \mathrm{O}_{4}$ & 93.4 & - & {$[62]$} \\
$\mathrm{MnFe}_{2} \mathrm{O}_{4}-$ graphene & $\sim 99$ & 0.0097 & {$[63]$} \\
$\mathrm{WO}_{3} / \mathrm{g}-\mathrm{C}_{3} \mathrm{~N}_{4}$ & 95 & 0.01897 & {$[64]$} \\
$\mathrm{Fe}_{2} \mathrm{TiO}_{5}$ & $\sim 100$ & 0.016 & {$[65]$} \\
$\mathrm{T}_{-}-\mathrm{BVO}-600$ & 98.93 & 0.0184 & {$[66]$} \\
\hline
\end{tabular}

\subsection{Photocatalytic Mechanisms}

Figure 9 shows the photocatalysis mechanism of BiOBr-G under visible light irradiation. The excitation of the electrons $\left(\mathrm{e}^{-}\right)$of the VB into the $\mathrm{CB}$ under visible light irradiation leads to the generation of electron-hole pairs. The $\mathrm{E}_{\mathrm{CB}}$ and $\mathrm{E}_{\mathrm{VB}}$ of $\mathrm{BiOBr}$ were evaluated using the equation below [67]:

$$
\begin{gathered}
\mathrm{E}_{\mathrm{VB}}=\chi-\mathrm{E}_{\mathrm{e}}+0.5 \mathrm{E}_{\mathrm{g}} \\
\mathrm{E}_{\mathrm{CB}}=\mathrm{E}_{\mathrm{V}}-\mathrm{E}_{\mathrm{g}}
\end{gathered}
$$

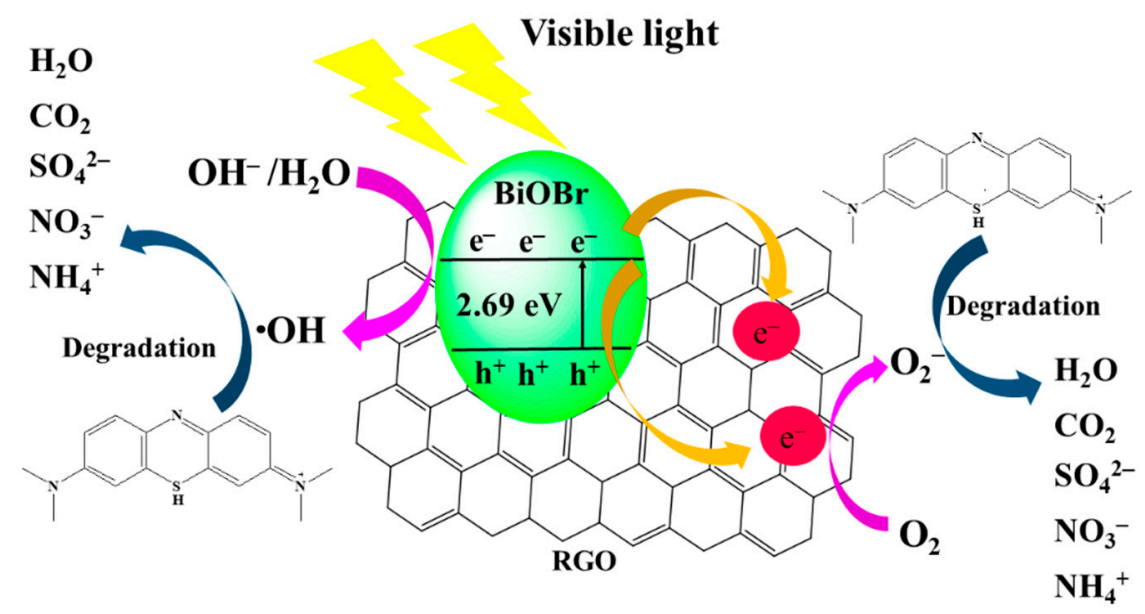

Figure 9. The photocatalytic mechanism diagram.

According to the DRS measurements, $\mathrm{E}_{\mathrm{e}}$ is $4.5 \mathrm{eV}$, and it represents the energy of free electrons on the hydrogen scale. In addition, $\mathrm{E}_{\mathrm{VB}}$ and $\mathrm{E}_{\mathrm{CB}}$ correspond to the edge potentials of $\mathrm{VB}$ and $\mathrm{CB}$, respectively. From the DRS results, $\chi$ is semiconductor electronegativity. The $\chi$ of $\mathrm{BiOBr}$ was $6.17 \mathrm{eV}$, and the $\mathrm{E}_{\mathrm{g}}$ of $\mathrm{BiOBr}-\mathrm{G}$ was $2.69 \mathrm{eV}$. Using the afore-mentioned equation, the $\mathrm{E}_{\mathrm{VB}}$ and $\mathrm{E}_{\mathrm{CB}}$ of $\mathrm{BiOBr}$ are approximately 3.02 and $0.33 \mathrm{eV}$, respectively [68]. The VB position of $\mathrm{BiOBr}$ is above $\mathrm{OH}^{-} / \bullet \mathrm{OH}(2.38 \mathrm{eV}$ to Normal Hydrogen Electrode, $\mathrm{NHE})$ and $\mathrm{H}_{2} \mathrm{O} / \bullet \mathrm{OH}(2.72 \mathrm{eV}$ to $\mathrm{NHE}$ ) [69]. The photogenerated electron-hole of $\mathrm{BiOBr}$ can oxidize $\mathrm{OH}^{-}$and $\mathrm{H}_{2} \mathrm{O}$ to the $\bullet \mathrm{OH}$ free radicals, and $\bullet \mathrm{OH}$ can degrade the $\mathrm{MB}$ molecules.

The RGO exhibits an extremely efficient electron collection and separation structure. After the charge separation of $\mathrm{BiOBr}$, the excited electrons were transferred to the $\mathrm{RGO}$ surface, thus decreasing the rate of electron-hole recombination [70]. Photogenerated electrons reacted with $\mathrm{O}_{2}$ molecules adsorbed on the surface of the RGO to produce $\mathrm{O}_{2}{ }^{-}$radicals. Simultaneously, the $\mathrm{OH}^{-}$and $\mathrm{H}_{2} \mathrm{O}$ reacted with the holes in the VB, thus generating $\bullet \mathrm{OH}$ radicals. The $\mathrm{RGO}$ nanosheets enhanced the electron-hole pair separation 
and also increased the adsorption of reactants owing to $\pi-\pi$ interactions and electrostatic force effects. In addition, the high surface area of RGO facilitated the adsorption of MB and the active oxides $\left(\mathrm{O}_{2}{ }^{-}\right.$and $\bullet \mathrm{OH}$ radicals $)$, thus enhancing the contact probability with radical and dye molecules and enhancing the photocatalytic activity of the catalyst. Finally, the $\mathrm{MB}$ molecules were degraded by $\mathrm{O}_{2}{ }^{-}$and $\bullet \mathrm{OH}$ radicals, thus producing non-toxic small molecules $\left(\mathrm{H}_{2} \mathrm{O}, \mathrm{CO}_{2}, \mathrm{SO}_{4}{ }^{2-}, \mathrm{NO}_{3}{ }^{-}\right.$, and $\left.\mathrm{NH}_{4}{ }^{+}\right)$. This photocatalytic process can be represented using the following chemical equation $[20,71]$.

$$
\begin{gathered}
\mathrm{BiOBr}+\mathrm{h} v \rightarrow \mathrm{e}-(\mathrm{BiOBr})+\mathrm{h}^{+}(\mathrm{BiOBr}) \\
\mathrm{e}^{-}+\mathrm{O}_{2} \rightarrow \mathrm{O}_{2}{ }^{-} \\
\mathrm{h}^{+}+\mathrm{OH}^{-} / \mathrm{H}_{2} \mathrm{O} \rightarrow \bullet \mathrm{OH} \\
\mathrm{h}^{+} / \mathrm{O}_{2}{ }^{-} / \bullet \mathrm{OH}+\mathrm{C}_{16} \mathrm{H}_{18} \mathrm{~N}_{3} \mathrm{ClS} \rightarrow \mathrm{H}_{2} \mathrm{O}+\mathrm{CO}_{2}+\mathrm{SO}_{4}{ }^{2-}+\mathrm{NO}_{3}{ }^{-}+\mathrm{NH}_{4}{ }^{+}
\end{gathered}
$$

\section{Conclusions}

In summary, in this study, BiOBr-G nanocomposites were successfully synthesized using a facile one-step microwave-assisted method and characterized by XRD, Raman, FTIR, SEM, TEM, UV-vis DRS, and PL. The XRD analysis confirmed the successful synthesis of GO, RGO, BiOBr, and all the BiOBr-G nanocomposites. However, the RGO diffraction peak was not observed in the XRD pattern of BiOBr-G. In addition, $D$ and $G$ bands were observed in the Raman spectrum of the BiOBr-G nanocomposites, indicating the graphene structure of the synthesized nanocomposite. Furthermore, a $\mathrm{Bi}-\mathrm{O}$ vibrational peak was observed in the FT-IR spectra of $\mathrm{BiOBr}$ and Bi-OBr-G. The SEM and TEM results revealed that the presence of $\mathrm{RGO}$ in the $\mathrm{BiOBr}-\mathrm{G}$ nanocomposites prevented the nanoparticles agglomeration and reduced the particle size. In addition, the band gap of $\mathrm{BiOBr}-\mathrm{G}$ was lower than that of $\mathrm{BiOBr}$, indicating that the addition of $\mathrm{RGO}$ to $\mathrm{BiOBr}$ enhanced the photocatalytic activity of $\mathrm{BiOBr}$. The PL results revealed that BiOBr-G exhibited higher quantum efficiency during the photocatalytic process compared to $\mathrm{BiOBr}$. The photocatalytic activity of the as-synthesized nanocomposites under visible light irradiation was investigated. BiOBr-G5 exhibited the optimum photocatalytic activity, and the removal percentage of MB achieved more than $96 \%$ in $75 \mathrm{~min}$. The prepared photocatalyst follows the first-order kinetic model, and the rate constant of BiOBr-G5 $\left(0.0392 \mathrm{~min}^{-1}\right)$ was higher than those of the other materials. These results were also superior to those of various catalysts reported in previous studies. The BiOBr-G nanocomposite synthesized in this study is an efficient, cost-effective, and environmentally friendly photocatalyst, with promising potential for wastewater treatment.

Author Contributions: K.-Y.S. conceptualized the idea and designed the experiments; Y.-L.K. performed the experiments; K.-Y.S., Y.-L.K., and E.-R.W. analyzed the data; K.-Y.S. funding acquisition; K.-Y.S., Y.-L.K., and E.-R.W. explained and visualized the data and wrote the manuscript. All authors have read and agreed to the published version of the manuscript.

Funding: This work was financially supported by the National Pingtung University of Taiwan (Grant No. NPTU-110-002 and Grant No. NPTU-110-009).

Institutional Review Board Statement: Not applicable.

Informed Consent Statement: Not applicable.

Data Availability Statement: All the data are available within the manuscript.

Conflicts of Interest: The authors declare no conflict of interest. 


\section{References}

1. Wang, Y.; Long, Y.; Yang, Z.; Zhang, D. A novel ion-exchange strategy for the fabrication of high strong BiOI/BiOBr heterostructure film coated metal wire mesh with tunable visible-light-driven photocatalytic reactivity. J. Hazard. Mater. 2018, 351, 11-19. [CrossRef]

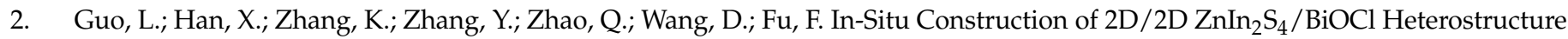
with Enhanced Photocatalytic Activity for N2 Fixation and Phenol Degradation. Catalysts 2019, 9, 729. [CrossRef]

3. Das, T.K.; Ganguly, S.; Bhawal, P.; Mondal, S.; Das, N.C. A facile green synthesis of silver nanoparticle-decorated hydroxyapatite for efficient catalytic activity towards 4-nitrophenol reduction. Res. Chem. Intermed. 2017, 44, 1189-1208. [CrossRef]

4. Wang, B.; An, W.; Liu, L.; Chen, W.; Liang, Y.; Cui, W. Novel Cu2S quantum dots coupled flower-like BiOBr for efficient photocatalytic hydrogen production under visible light. RSC Adv. 2014, 5, 3224-3231. [CrossRef]

5. Wang, D.; Liu, L.; Wang, Y.; Fan, C.; Huang, W. A new insight on the role of CQDs in driving BiOBr into broader-spectrumresponse: Dual function of up-conversion and photosensitization effect. Chem. Phys. Lett. 2020, 747, 137340. [CrossRef]

6. Qu, X.; Liu, M.; Li, L.; Wang, R.; Sun, H.; Shi, L.; Du, F. BiOBr flakes decoration and structural modification for CdTe/TiO2 spheres: Towards water decontamination under simulated light irradiation. Mater. Sci. Semicond. Process. 2019, 93, 331-338. [CrossRef]

7. Lv, J.; Hu, Q.; Cao, C.; Zhao, Y. Modulation of valence band maximum edge and photocatalytic activity of BiOX by incorporation of halides. Chemosphere 2018, 191, 427-437. [CrossRef]

8. Zhang, D.; Li, J.; Wang, Q.; Wu, Q. High $\{001\}$ facets dominated BiOBr lamellas: Facile hydrolysis preparation and selective visible-light photocatalytic activity. J. Mater. Chem. A 2013, 1, 8622-8629. [CrossRef]

9. Dashairya, L.; Sharma, M.; Basu, S.; Saha, P. SnS2/RGO based nanocomposite for efficient photocatalytic degradation of toxic industrial dyes under visible-light irradiation. J. Alloy Compd. 2019, 774, 625-636. [CrossRef]

10. Shivakumara, C.; Saraf, R.; Halappa, P. White luminescence in Dy 3+ doped BiOCl phosphors and their Judd-Ofelt analysis. Dye. Pigment. 2016, 126, 154-164. [CrossRef]

11. Zhao, Z.Y.; Dai, W.W. Structural, Electronic, and Optical Properties of Eu-Doped BiOX (X = F, Cl, Br, I): A DFT+U Study. Inorg. Chem 2014, 53, 13001-13011. [CrossRef]

12. Zhang, S.; Yang, J. Microwave-Assisted Synthesis of BiOCl/BiOBr Composites with Improved Visible-Light Photocatalytic Activity. Ind. Eng. Chem. Res. 2015, 54, 9913-9919. [CrossRef]

13. Liu, Y.; Xu, J.; Wang, L.; Zhang, H.; Xu, P.; Duan, X.; Sun, H.; Wang, S. Three-Dimensional BiOI/BiOX (X = Cl or Br) Nanohybrids for Enhanced Visible-Light Photocatalytic Activity. Nanomaterials 2017, 7, 64. [CrossRef] [PubMed]

14. Meng, X.; Li, Z.; Chen, J.; Xie, H.; Zhang, Z. Enhanced visible light-induced photocatalytic activity of surface-modified BiOBr with Pd nanoparticles. Appl. Surf. Sci. 2018, 433, 76-87. [CrossRef]

15. Vadivel, S.; Paul, B.; Maruthamani, D.; Kumaravel, M.; Vijayaraghavan, T.; Hariganesh, S.; Pothu, R. Synthesis of yttrium doped $\mathrm{BiOF} /$ RGO composite for visible light: Photocatalytic applications. Mater. Sci. Energy Technol. 2019, 2, 112-116. [CrossRef]

16. Gao, J.; Gao, Y.; Sui, Z.; Dong, Z.; Wang, S.; Zou, D. Hydrothermal synthesis of BiOBr/FeWO4 composite photocatalysts and their photocatalytic degradation of doxycycline. J. Alloy Compd. 2018, 732, 43-51. [CrossRef]

17. Liu, T.; Wang, Y. Synergistic effect of iodine doping and platinum loading on boosting the visible light photocatalytic activity of BiOBr. Inorg. Chem. Commun. 2020, 114, 107846. [CrossRef]

18. Ganguly, S.; Das, P.; Bose, M.; Das, T.K.; Mondal, S.; Das, A.K.; Das, N.C. Sonochemical green reduction to prepare Ag nanoparticles decorated graphene sheets for catalytic performance and antibacterial application. Ultrason. Sonochemistry 2017, 39, 577-588. [CrossRef]

19. Gomez-Ruiz, B.; Ribao, P.; Diban, N.; Rivero, M.; Ortiz, I.; Urtiaga, A. Photocatalytic degradation and mineralization of perfluorooctanoic acid (PFOA) using a composite TiO2 - rGO catalyst. J. Hazard. Mater. 2018, 344, 950-957. [CrossRef]

20. Liang, J.; Wei, Y.; Zhang, J.; Yao, Y.; He, G.; Tang, B.; Chen, H. Scalable Green Method to Fabricate Magnetically Separable NiFe2O4-Reduced Graphene Oxide Nanocomposites with Enhanced Photocatalytic Performance Driven by Visible Light. Ind. Eng. Chem. Res. 2018, 57, 4311-4319. [CrossRef]

21. Liu, J.; Wang, Z.; Liu, L.; Chen, W. Reduced graphene oxide as capturer of dyes and electrons during photocatalysis: Surface wrapping and capture promoted efficiency. Phys. Chem. Chem. Phys. 2011, 13, 13216-13221. [CrossRef]

22. Patil, S.S.; Mail, M.G.; Hassan, M.A.; Patil, D.R.; Kolekar, S.S.; Ryu, S.W. One-Pot in Situ Hydrothermal Growth of BiVO4/Ag/rGO Hybrid Architectures for Solar Water Splitting and Environmental Remediation. Sci. Rep. 2017, 7, 8404. [CrossRef] [PubMed]

23. Lee, J.; Dong, X.; Dong, X. Ultrasonic synthesis and photocatalytic characterization of H3PW12O40/TiO2 (anatase). Ultrason Sonochem. 2010, 17, 649-653. [CrossRef] [PubMed]

24. Vadivel, S.; Keerthi, P.; Vanitha, M.; Muthukrishnaraj, A.; Balasubramanian, N. Solvothermal synthesis of Sm-doped BiOBr/RGO composite as an efficient photocatalytic material for methyl orange degradation. Mater. Lett. 2014, 128, 287-290. [CrossRef]

25. Behera, A.; Kandi, D.; Mansingh, S.; Martha, S.; Parida, K. Facile synthesis of ZnFe2O4@RGO nanocomposites towards photocatalytic ciprofloxacin degradation and H2 energy production. J. Colloid Interface Sci. 2019, 556, 667-679. [CrossRef]

26. Farhadian, N.; Akbarzadeh, R.; Pirsaheb, M.; Jen, T.-C.; Fakhri, Y.; Asadi, A. Chitosan modified N, S-doped TiO2 and N, S-doped $\mathrm{ZnO}$ for visible light photocatalytic degradation of tetracycline. Int. J. Biol. Macromol. 2019, 132, 360-373. [CrossRef] [PubMed] 
27. Arab Chamjangali, M.; Bagherian, G.; Javid, A.; Boroumand, S.; Farzaneh, N. Synthesis of Ag-ZnO with multiple rods (multipods) morphology and its application in the simultaneous photo-catalytic degradation of methyl orange and methylene blue. Spectrochim. Acta A Mol. Biomol. Spectrosc. 2015, 150, 230-237. [CrossRef]

28. Kumar, R.; Rashid, J.; Barakat, M. Zero valent Ag deposited TiO2 for the efficient photocatalysis of methylene blue under UV-C light irradiation. Colloid Interface Sci. Commun. 2015, 5, 1-4. [CrossRef]

29. Liang, J.; Liu, F.; Li, M.; Liu, W.; Tong, M. Facile synthesis of magnetic Fe3O4@BiOI@AgI for water decontamination with visible light irradiation: Different mechanisms for different organic pollutants degradation and bacterial disinfection. Water Res. 2018, 137, 120-129. [CrossRef]

30. Shenawi-Khalil, S.; Uvarov, V.; Fronton, S.; Popov, I.; Sasson, Y. A Novel Heterojunction BiOBr/Bismuth Oxyhydrate Photocatalyst with Highly Enhanced Visible Light Photocatalytic Properties. J. Phys. Chem. C 2012, 116, 11004-11012. [CrossRef]

31. Jiang, T.; Li, J.; Sun, Z.; Liu, X.; Lu, T.; Pan, L. Reduced graphene oxide as co-catalyst for enhanced visible light photocatalytic activity of BiOBr. Ceram. Int. 2016, 42, 16463-16468. [CrossRef]

32. Janani, S.; Sudha Rani, K.S.; Ellappan, P.; Miranda, L.R. Photodegradation of methylene blue using magnetically reduced graphene oxide bismuth oxybromide composite. J. Environ. Chem. Eng. 2016, 4, 534-541.

33. Kumar, A.; Kuang, Y.; Liang, Z.; Sun, X. Microwave chemistry, recent advancements, and eco-friendly microwave-assisted synthesis of nanoarchitectures and their applications: A review. Mater. Today Nano 2020, 11, 100076. [CrossRef]

34. Muzyka, R.; Kwoka, M.; Smędowski, Ł.; Díez, N.; Gryglewicz, G. Oxidation of graphite by different modified Hummers methods New Carbon Mater. 2017, 32, 15-20. [CrossRef]

35. Gupta, B.; Kumar, N.; Panda, K.; Kanan, V.; Joshi, S.; Visoly-Fisher, I. Role of oxygen functional groups in reduced graphene oxide for lubrication. Sci. Rep. 2017, 7, srep45030. [CrossRef]

36. Li, S.; Chen, J.; Jiang, W.; Liu, Y.; Ge, Y.; Liu, J. Facile construction of flower-like bismuth oxybromide/bismuth oxide formate p-n heterojunctions with significantly enhanced photocatalytic performance under visible light. J. Colloid Interface Sci. 2019, 548, 12-19. [CrossRef]

37. Allagui, L.; Chouchene, B.; Gries, T.; Medjahdi, G.; Girot, E.; Framboisier, X.; Amara, A.B.H.; Balan, L.; Schneider, R. Core/shell rGO/BiOBr particles with visible photocatalytic activity towards water pollutants. Appl. Surf. Sci. 2019, 490, 580-591. [CrossRef]

38. Chen, P.; Xing, X.; Xie, H.; Sheng, Q.; Qu, H. High catalytic activity of magnetic CuFe2O4/graphene oxide composite for the degradation of organic dyes under visible light irradiation. Chem. Phys. Lett. 2016, 660, 176-181. [CrossRef]

39. Gurushantha, K.; Anantharaju, K.S.; Renuka, L.; Sharma, S.C.; Nagaswarupa, H.P.; Prashantha, S.C.; Vidya, Y.S.; Nagabhushana, $\mathrm{H}$. New green synthesized reduced graphene oxide- $\mathrm{ZrO} 2$ composite as high performance photocatalyst under sunlight. RSC Adv. 2017, 7, 12690-12703. [CrossRef]

40. Jiao, X.; Qiu, Y.; Zhang, L.; Zhang, X. Comparison of the characteristic properties of reduced graphene oxides synthesized from natural graphites with different graphitization degrees. RSC Adv. 2017, 7, 52337-52344. [CrossRef]

41. Chen, J.; Xiao, X.; Wang, Y.; Lu, M.; Zeng, X. Novel AgI/BiOBr/reduced graphene oxide Z-scheme photocatalytic system for efficient degradation of tetracycline. J. Alloy. Compd. 2019, 800, 88-98. [CrossRef]

42. Xu, G.; Li, M.; Wang, Y.; Zheng, N.; Yang, L.; Yu, H.; Yu, Y. A novel Ag-BiOBr-rGO photocatalyst for enhanced ketoprofen degradation: Kinetics and mechanisms. Sci. Total Environ. 2019, 678, 173-180. [CrossRef] [PubMed]

43. Mishra, A.; Singh, V.K.; Mohanty, T. Coexistence of interfacial stress and charge transfer in graphene oxide-based magnetic nanocomposites. J. Mater. Sci. 2017, 52, 7677-7687. [CrossRef]

44. Tu, X.; Luo, S.; Chen, G.; Li, J. One-Pot Synthesis, Characterization, and Enhanced Photocatalytic Activity of a BiOBr-Graphene Composite. Chem. Eur. J. 2012, 18, 14359-14366. [CrossRef]

45. Cui, Z.; Song, H.; Ge, S.; He, W.; Liu, Y. Fabrication of $\mathrm{BiOCl} / \mathrm{BiOBr}$ hybrid nanosheets with enhanced superoxide radical dominating visible light driven photocatalytic activity. Appl. Surf. Sci. 2019, 467-468, 505-513. [CrossRef]

46. Zhang, Z.; Ge, X.; Zhang, X.; Duan, L.; Li, X.; Yang, Y.; Lü, W. A sea cucumber-like BiOBr nanosheet/Zn2GeO4 nanorod heterostructure for enhanced visible light driven photocatalytic activity. Mater. Res. Express 2017, 5, 015009. [CrossRef]

47. Siddiqui, S.; Siddiqui, Z.N. Synthesis and catalytic evaluation of PVP-CeO2/rGO as a highly efficient and recyclable heterogeneous catalyst for multicomponent reactions in water. Nanoscale Adv. 2020, 2, 4639-4651. [CrossRef]

48. Ma, J.; Ding, J.; Yu, L.; Li, L.; Kong, Y.; Komarneni, S. BiOCl dispersed on NiFe-LDH leads to enhanced photo-degradation of Rhodamine B dye. Appl. Clay Sci. 2015, 109-110, 76-82. [CrossRef]

49. Geng, A.; Meng, L.; Han, J.; Zhong, Q.; Li, M.; Han, S.; Mei, C.; Xu, L.; Tan, L.; Gan, L. Highly efficient visible-light photocatalyst based on cellulose derived carbon nanofiber/BiOBr composites. Cellul. 2018, 25, 4133-4144. [CrossRef]

50. Sarwan, B.; Acharya, A.D.; Kaur, S.; Pare, B. Visible light photocatalytic deterioration of polystyrene plastic using supported BiOCl nanoflower and nanodisk. Eur. Polym. J. 2020, 134, 109793. [CrossRef]

51. Xu, J.; Meng, W.; Zhang, Y.; Li, L.; Guo, C. Photocatalytic degradation of tetrabromobisphenol A by mesoporous BiOBr: Efficacy, products and pathway. Appl. Catal. B: Environ. 2011, 107, 355-362. [CrossRef]

52. Wu, S.; Wang, P.; Cai, Y.; Liang, D.; Ye, Y.; Tian, Z.; Liu, J.; Liang, C. Reduced graphene oxide anchored magnetic ZnFe2O4 nanoparticles with enhanced visible-light photocatalytic activity. RSC Adv. 2014, 5, 9069-9074. [CrossRef]

53. Pan, Y.; Wu, D. The rGO/BiOBr/Bi4 O5 Br2 Composites with Stacked Nanosheets for Ciprofloxacin Photodegradation under Visible Light Irradiation. Z. Anorg. Allg. Chem. 2019, 645, 1153-1160. [CrossRef] 
54. Li, X.; Dong, C.; Wu, K.-L.; Xia, S.-H.; Hu, Y.; Ling, M.; Liu, K.; Lu, X.-L.; Ye, Y.; Wei, X.-W. Synthesis of nitrogen-doped graphene-BiOBr nanocomposites with enhanced visible light photocatalytic activity. Mater. Lett. 2015, 164, 502-504. [CrossRef]

55. Gao, D.; Shi, Z.; Xu, Y.; Zhang, J.; Yang, G.; Zhang, J.; Wang, X.; Xue, D. Synthesis, Magnetic Anisotropy and Optical Properties of Preferred Oriented Zinc Ferrite Nanowire Arrays. Nanoscale Res. Lett. 2010, 5, 1289-1294. [CrossRef] [PubMed]

56. Behera, A.; Kandi, D.; Majhi, S.M.; Martha, S.; Parida, K. Facile synthesis of ZnFe2O4 photocatalysts for decolourization of organic dyes under solar irradiation. Beilstein J. Nanotechnol. 2018, 9, 436-446. [CrossRef] [PubMed]

57. Jing, L.; Qu, Y.; Wang, B.; Li, S.; Jiang, B.; Yang, L.; Fu, W.; Fu, H.; Sun, J. Review of photoluminescence performance of nano-sized semiconductor materials and its relationships with photocatalytic activity. Sol. Energy Mater. Sol. Cells 2006, 90, $1773-1787$.

58. Fan, W.; Zhu, Z.; Yu, Y.; Liu, Z.; Li, C.; Huo, P.; Qiu, Y.; Yan, Y. Fabrication of magnetic g-C3N4 for effectively enhanced tetracycline degradation with RGO as mediator. New J. Chem. 2018, 42, 15974-15984. [CrossRef]

59. Ao, M.; Liu, K.; Tang, X.; Li, Z.; Peng, Q.; Huang, J. BiOCl/TiO2/diatomite composites with enhanced visible-light photocatalytic activity for the degradation of rhodamine B. Beilstein J. Nanotechnol. 2019, 10, 1412-1422. [CrossRef]

60. Liu, H.; Yang, C.; Jin, X.; Zhong, J.; Li, J. One-pot hydrothermal synthesis of MXene Ti3C2/TiO2/BiOCl ternary heterojunctions with improved separation of photoactivated carries and photocatalytic behavior toward elimination of contaminants. Colloids Surf. A Physicochem. Eng. Asp. 2020, 603, 125239. [CrossRef]

61. Zhang, D.; Su, C.; Yao, S.; Li, H.; Pu, X.; Geng, Y. Facile in situ chemical transformation synthesis, boosted charge separation, and increased photocatalytic activity of $\mathrm{BiPO} 4 / \mathrm{BiOCl}$ p-n heterojunction photocatalysts under simulated sunlight irradiation. J. Phys. Chem. Solids 2020, 147, 109630. [CrossRef]

62. Harish, K.N.; Bhojya Naik, H.S.; Prashanth kumar, P.N.; Viswanath, R. Optical and Photocatalytic Properties of Solar Light Active Nd-Substituted Ni Ferrite Catalysts: For Environmental Protection. ACS Sustain. Chem. Eng. 2013, 1, 1143-1153. [CrossRef]

63. Fu, Y.; Xiong, P.; Chen, H.; Sun, X.; Wang, X. High Photocatalytic Activity of Magnetically Separable Manganese Ferrite-Graphene Heteroarchitectures. Ind. Eng. Chem. Res. 2012, 51, 725-731. [CrossRef]

64. Liu, X.; Jin, A.; Jia, Y.; Xia, T.; Deng, C.; Zhu, M.; Chen, C.; Chen, X. Synergy of adsorption and visible-light photocatalytic degradation of methylene blue by a bifunctional Z-scheme heterojunction of WO3/g-C3N4. Appl. Surf. Sci. 2017, 405, 359-371. [CrossRef]

65. Vasiljevic, Z.Z.; Dojcinovic, M.P.; Vujancevic, J.D.; Jankovic-Castvan, I.; Ognjanović, M.; Tadic, N.B.; Stojadinovic, S.; Brankovic, G.O.; Nikolic, M.V. Photocatalytic degradation of methylene blue under natural sunlight using iron titanate nanoparticles prepared by a modified sol-gel method. R. Soc. Open Sci. 2020, 7, 200708. [CrossRef]

66. Nguyen, V.H.; Bui, Q.T.P.; Vo, D.-V.N.; Lim, K.T.; Bach, L.G.; Do, S.T.; Van Nguyen, T.; Doan, V.-D.; Nguyen, T.-D.; Nguyen, T.D. Effective Photocatalytic Activity of Sulfate-Modified BiVO4 for the Decomposition of Methylene Blue Under LED Visible Light. Materials 2019, 12, 2681. [CrossRef] [PubMed]

67. Li, Y.; Wu, M.; Wang, Q.; Wang, K.; Zhang, H.; Quan, X.; Zhang, B.; Yang, D. High-Efficiency Visible Light Responsive Sulfide $\mathrm{KSb}_{5} \mathrm{~S}_{8}$ Photocatalyst with a Layered Crystal Structure. Catalysts 2019, 9, 529. [CrossRef]

68. Yang, Z.; Li, J.; Cheng, F.; Chen, Z.; Dong, X. BiOBr/protonated graphitic C3N4 heterojunctions: Intimate interfaces by electrostatic interaction and enhanced photocatalytic activity. J. Alloy. Compd. 2015, 634, 215-222. [CrossRef]

69. Wu, X.; Li, H.; Zhang, Y.; Zhang, J.; Su, J.; Feng, Y.; Zhang, W.; Sun, L.; Sun, X. Synthesis of AgI/WS 2 hybrids as a novel photocatalyst with efficient degradation of rhodamine B. Micro Nano Lett. 2019, 14, 173-177. [CrossRef]

70. Zheng, M.; Ma, X.; Hu, J.; Zhang, X.; Li, D.; Duan, W. Novel recyclable BiOBr/Fe3O4/RGO composites with remarkable visible-light photocatalytic activity. RSC Adv. 2020, 10, 19961-19973. [CrossRef]

71. Zhang, B.; Zhang, M.; Zhang, L.; Bingham, P.A.; Li, W.; Kubuki, S. PVP surfactant-modified flower-like BiOBr with tunable bandgap structure for efficient photocatalytic decontamination of pollutants. Appl. Surf. Sci. 2020, 530, 147233. [CrossRef] 